\section{Evaluation of a multifaceted social marketing campaign to increase awareness of and screening for oral cancer in African Americans}

Jedele JM, Ismail AI. Evaluation of a multifaceted social marketing campaign to increase awareness of and screening for oral cancer in African Americans. Community Dent Oral Epidemiol 2010; 38: 371-382.

(c) 2010 John Wiley \& Sons A/S

Abstract-Objectives: A 2-year social marketing media campaign and community education activities were organized to promote screening for oral cancer in a high-risk population in Detroit/Wayne County, Michigan. Longterm goals of the campaign were to reduce the oral cancer death rate, increase the proportion of oral cancers detected at an early stage, and increase the proportion of adults who report having been screened. The intermediate goals of the campaign were to increase awareness of oral cancer and of oral cancer screening. This article presents outcomes related to the intermediate goals of the campaign. Methods: The intermediate goals of the campaign were assessed by the number of calls to a toll-free hotline, which media venues led to calls, number of screenings conducted by the free screening clinic, number of precancers and cancers detected, and the number of sessions conducted, organizations involved, and persons participating in the community education program. The costs per screened case and cancers detected were also evaluated. The media campaign promoted screening using billboards, radio and newspaper ads, and a toll-free hotline. Culturally relevant messages were developed collaboratively with focus groups representing the target audience. Billboards were placed in highly visible locations around Detroit, Michigan. Sixty-second messages on the impact of oral cancer and that screening is 'painless and free' were aired on radio stations popular with the target audience. Ads displaying the hotline were placed in two local newspapers. Callers to the hotline were scheduled for a free screening with a clinic operated by the project. Referral to an oral surgeon was scheduled if a suspicious lesion was found. Free education sessions were also conducted with community-based organizations. Costs associated with the campaign and hotline were totaled, and the cost per screening and cancer detected were calculated.

Results: During the campaign, 1327 radio spots aired; 42 billboards were displayed; two newspaper ads were printed; and 242 education sessions were conducted. The hotline received 1783 calls. The majority of callers reported that their call was prompted by a radio ad (57\%). The clinic screened 1020 adults and referred 78 for further examination. Three cancers, two precancers, and 12 benign tumors were detected. The total cost associated with the campaign and toll-free hotline was $\$ 795,898$. Conclusions: A multifaceted social marketing campaign including radio ads, billboards, and education sessions can effectively target a high-risk population and that given an outlet could result in a significant number of people getting screened at a relatively low cost.

\section{J.M. Jedele and A.I. Ismail}

Detroit Oral Cancer Prevention Project, School of Dentistry, University of Michigan, 1011 N. University Ave, Ann Arbor, MI, USA

Key words: mass media; oral cancer; screening; social marketing

Jenefer Margaret Jedele, Detroit Oral Cancer Prevention Project, School of Dentistry D2361, University of Michigan, 1011 N. University Ave, Ann Arbor, MI 48109-1078, USA

Tel.: +734 6157186

Fax: +7349361597

e-mail: jwillem@umich.edu

Submitted 9 February 2009; accepted 25 February 2010 
Oral cancer affects African Americans more than other racial or ethnic groups. It is the fourth most common cancer in African-American men in the United States (1). The age-adjusted incidence of oral cancer for African-American men in the United States from 2000 to 2003 was 18.0 per 100000 versus 15.7 per 100000 for white men (2). The American Cancer Society estimates 2590 new oral cancer cases and 840 deaths among AfricanAmerican men in 2007 (2). The age-adjusted death rate caused by oral cancer for African-American men from 2000 to 2003 was 6.8 versus 3.8 for white men. Also African-American men die at an earlier age (60 years) versus white men (66 years) (2) and had a 5-year survival rate almost half that of white men (36.1 versus 61.0) between 1996 and 2004 (1).

The disparities in oral cancer incidence and mortality that exist at the national level between African Americans and whites are amplified at the state and local level for Wayne County/Detroit, Michigan. Kolker et al. 2007 examined Surveillance Epidemiology and End Results Program (SEER) data for incidence, mortality, and survival rates for the city of Detroit and Wayne County, Michigan. Between 1993 and 2002, a total of 10744 new cases of oral cancer were detected in Michigan, 5032 $(47 \%)$ of which were in the Detroit tri-county area. The highest incidence rate for African Americans was in Wayne County, which includes the city of Detroit where $82 \%$ of the residents are African American (3). In Michigan during this same period, African Americans had a 1.3 times higher incidence rate than white Americans, and African-American men had an incidence rate 1.5 times higher than white-American men. Older African-American men (50-74 years) had an incidence rate 1.7 times higher than the rate of their white counterparts. Kolker et al. reported that $46 \%$ of all oral cancer deaths in Michigan between 1993 and 2002 occurred in the Detroit Tri-county area, and the mortality rate in Wayne County was 1.3 times higher, and the rate in Detroit 1.7 times higher than the rate for the entire state. The death rate during this period for African-American men in Detroit increased at a greater rate than in the rest of Michigan.

Diagnosing oral cancer at an early stage greatly improves the chances of survival. The 5-year survival rate for persons diagnosed at a localized stage is $81 \%$; once the cancer has become regionalized, the 5-year survival rate decreases to $51 \%$ (1). Despite the importance of early detection, only $28.3 \%$ of oral cancers in Detroit between 2000 and
2002 were detected at an early stage versus $37.6 \%$ for the state and $33.0 \%$ nationally (4).

The average American has limited knowledge about risk factors and signs of oral cancer (5-11), and few have been screened for oral cancer $(10,12$, 13). African Americans seem to have an even more limited knowledge of oral cancer than white Americans $(5,10,14,15)$ and are less likely than other races to have been screened for oral cancer ( 7 , $10,12,13)$.

Social marketing has proven to be a promising intervention for changing health behaviors. The basis for social marketing in public health is that techniques used successfully to promote products in commercial business could successfully be applied to promote social causes (16-19). Social marketing campaigns may be designed using different behavioral models; however, the messaging must be tailored to the knowledge level and cues to actions for behavioral change in the targeted audience. The goal is to benefit the target audience by changing negative behaviors to more positive ones.

Mass media has most frequently been employed as the mode of information dissemination in social marketing campaigns. The use of mass media social marketing campaigns has successfully impacted awareness of, attitudes about, and intentions toward screening for many cancers, such as breast and cervical cancer (20-23), colon cancer (24), and oral cancer (25). A systematic review (26) found that mass media social marketing has been successful at 'selling' positive behaviors, knowledge, and attitudes related to a range of healthrelated topics such as nutrition, exercise, and cigarette, alcohol, and illicit drug use.

Despite the success of many of these campaigns in increasing awareness, they have been less successful in actually changing screening behavior. A basic principle of social marketing is knowing the target audience, how they view a particular situation, and why they behave the way they do. Campaigns with directed messages or that are culturally relevant have been more successful in increasing screening rates $(27,28)$ as have campaigns that utilize lay and community health workers (29-33).

Social marketers are also aware that the behaviors they seek to change must be given a readily available outlet for those who are willing to act. When a screening program is linked with a media campaign, significant increases in screening rates are realized $(21,31)$, and early detection can be increased $(28,34)$. By including a free screening program with the campaign, an outlet is made 
available to those who are motivated to act by removing or reducing barriers to access.

To address the need for early detection of oral cancer in African-American men in Detroit, a multifaceted mass media social marketing campaign and community outreach program was designed and implemented in Detroit, Michigan. The campaign promoted screening and early detection through culturally relevant messages, community-based education, and a free screening program. This article presents the intermediate outcomes of the Detroit Oral Cancer Prevention Project's mass media campaign. The interim outcomes evaluated include the number of calls to the toll-free hotline and which media venues led to the calls, the number of screenings conducted by the project's free screening clinic, the number of precancers and cancers detected, number of education sessions conducted, and the costs associated with screening and cancers detected.

\section{Methods}

\section{Media campaign}

A 2-year mass media campaign (March 2005 through December 2007) was introduced to promote screening for oral cancer in Detroit/Wayne County, Michigan. The design of the media campaign was based on the Pull strategy used in marketing campaigns (35). The Pull strategy targets advertising and promotions to the public who in turn will ask for the service from healthcare providers. The media campaign was focused on African-American adults 40+ years of age in the Detroit/Wayne County area. The messages chosen for the campaign were created by conducting nine focus groups with community groups in the Detroit/Wayne County area and with members of the target population. A professional health marketing company was also enlisted to assist and to advise on the design and implementation of the campaign. The billboards displayed strong visual images, such as 'Can't sing?', 'Can't kiss?', 'Can't taste?' ‘Oral Cancer? Get Checked. It's Painless \& Free', and the project's toll-free informational number (Fig. 1). The outdoor billboards were placed in highly visible locations within and around the target area only. Billboards were scheduled to run in flights, or display periods, to reduce the cost while maintaining reach and frequency. Each billboard flight lasted approximately 17 weeks with $4-8$ weeks between flights.

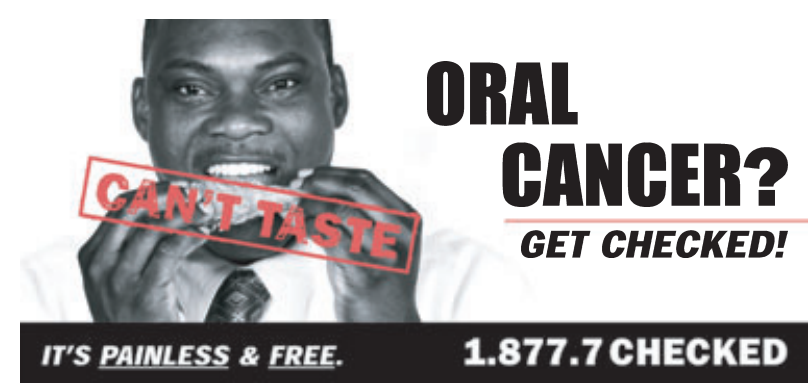

Fig. 1. Detroit Oral Cancer Prevention Project billboard.

Radio spots reinforced the campaign's message and allowed the project to deliver more detailed information about oral cancer and its causes as well as the ease and location of screenings. Five 60 -second radio spots were produced and aired in 2-week intervals (2 weeks on followed by 2 weeks off) for a total of 42 weeks. The content of the radio spots included messages about losing the ability to taste and enjoy foods, the ability to enjoy kissing, as well as information about getting checked before it's too late. The radio spots were read by a local radio personality, a city council member, and two local African-American dentists. Prime time spots were purchased to ensure a wider audience. Radio spots could be heard between 6:00 am and 12:00 am EST. Three radio stations were selected based on their popularity with the target audience to run the project's radio spots.

Print advertising in two local newspapers further reinforced the key messages delivered through the billboards and radio spots. Three newspaper ads ran for 2 weeks on followed by 1 week off for the first 5 months of the media campaign in each of the local newspapers. The layout of the newspaper ads was the same as the billboards with additional facts on oral cancer printed at the bottom of the ad. Additionally, brochures were printed with the same messages as those displayed on the billboards and discussed in the radio spots. The brochures provided more detailed information on the symptoms of and risk factors for oral cancer, a description of what to expect during an oral cancer screening, as well as the project's toll-free number. Brochures were distributed to health clinics, churches, and other local community organizations in Detroit/Wayne County.

\section{Toll-free number}

A project dedicated toll-free number was established to provide information on oral cancer and to schedule callers for screening appointments at a clinic operated by the project. The toll-free number 
was operated 24-hours a day, 7 days a week throughout the campaign period by a local community service organization experienced in hosting hotlines for various issues such as suicide and gambling addiction. Callers to the project's tollfree number were asked whether they wished to participate in the project by answering a few questions and to schedule an appointment for a free screening at the clinic operated by the project. Those who consented were asked to report on demographic characteristics, symptoms, risk factors, and the source which prompted their call. Those not consenting were still offered the opportunity to schedule an appointment for a free screening.

\section{Screening clinic}

A free screening clinic located in a central area within the city of Detroit was operated for 1 day each week. A dentist was hired by the project to provide screenings at the screening clinic. Prior to the start of screening, the project dentist was trained one-on-one by a clinical oral pathologist in the conduct of oral cancer screening and identification of oral cancer. At the clinic, participants completed consent forms and a brief questionnaire that included an assessment of symptoms, tobacco and alcohol history, an evaluation of the mass media campaign, and demographic information.

During the screening, the dentist completed a clinical evaluation form noting any white, red, or mixed lesions, swelling, or enlargement or tenderness of the lymph glands. If the dentist noticed anything that may be suspicious of oral cancer, a referral to an oral surgeon was scheduled by the project staff prior to the patient leaving the clinic. Referrals were tracked to determine the final diagnosis and to assist in rescheduling if necessary.

\section{Outreach}

In addition to the media campaign, a community outreach program was implemented. Three community members were hired and trained as health educators to present a 30-minute education session using a flipchart. The material presented included information on the project and its goals, what oral cancer is and what it looks like, risk factors, prevention, and the screening process. After an initial 1-day training, health educators were observed periodically to assure adherence to the education session materials. Sessions were scheduled with community organizations within Detroit/Wayne County using pre-existing lists from a neighborhood association and City of Detroit guides of organizations, block clubs, and religious and faith-based organizations. Contact with organizations was initiated by project staff, and an attempt to schedule the organization for a session was made. The project also attempted to reach out to organizations by placing an ad in a local magazine. The ad encouraged organizations to call the project to schedule a free education session. Finally, health educators were encouraged to schedule sessions with organizations with which they already had a relationship.

Participants in the education sessions were members of or visitors to the community organization in which the session was conducted. All participants were invited to complete a questionnaire prior to the start of the session (presession) and a questionnaire at the end of the session (postsession). The questionnaires assessed participants' knowledge about oral cancer, awareness of risk factors, experience with and desire for screening, and awareness of the Detroit Oral Cancer Prevention Project.

\section{Evaluation}

The evaluation of the effectiveness of the mass media campaign included summarizing the intermediate outcomes: the number of calls to the toll-free hotline and which media venues led to the calls, the number of screenings conducted by the free screening clinic, and the number of precancers and cancers detected. The number of education sessions conducted was used to evaluate outreach into the community. The project also tracked the costs associated with the media campaign and screening. The media campaign was further assessed by evaluating the cost per screened case and cost per cancer diagnosis.

\section{Statistical analyses}

Data were analyzed using SAS 9.1 (SAS Institute Inc., Cary, NC, USA; 2004). Descriptive statistics were computed for the callers to the toll-free number, persons screened and their results, and education sessions. Repeated measures analyses were conducted to compare the pre- and postsession responses to determine whether education session participants' knowledge of oral cancer improved. Missing data were not imputed.

\section{Results}

\section{Toll-free callers}

The toll-free number received a total of 1791 calls. Ninety-four percent of the callers consented and 
Table 1. Characteristics of callers to the toll-free number

\begin{tabular}{|c|c|c|}
\hline & $N$ & $\%$ \\
\hline Total & 1791 & 100.0 \\
\hline Consenting/eligible & 1684 & 94.0 \\
\hline \multicolumn{3}{|l|}{ Gender } \\
\hline Male & 1081 & 66.7 \\
\hline Female & 540 & 33.3 \\
\hline \multicolumn{3}{|l|}{ Race } \\
\hline Black & 1456 & 90.3 \\
\hline White & 66 & 4.1 \\
\hline Other & 90 & 5.6 \\
\hline \multicolumn{3}{|l|}{ Age } \\
\hline 29 years or younger & 178 & 11.0 \\
\hline 30-39 years & 342 & 21.1 \\
\hline 40-49 years & 499 & 30.8 \\
\hline 50-59 years & 430 & 26.6 \\
\hline 60-69 years & 118 & 7.3 \\
\hline 70-79 years & 38 & 2.4 \\
\hline $80+$ years & 13 & 0.8 \\
\hline \multicolumn{3}{|l|}{ Risk factors } \\
\hline Use tobacco/alcohol & 1326 & 83.8 \\
\hline \multicolumn{3}{|l|}{ Symptoms (check all that apply) } \\
\hline Sore throat/caught in throat & 436 & 27.6 \\
\hline Hoarseness/voice changes & 416 & 26.5 \\
\hline Lump on one side of mouth or cheek & 237 & 15.0 \\
\hline Persistent ear pain & 202 & 12.8 \\
\hline Lump in neck, behind ear, under jaw & 198 & 12.7 \\
\hline Numbness of tongue/other area & 196 & 12.4 \\
\hline Sore on lips for $2+$ weeks & 167 & 10.5 \\
\hline Swelling causing dentures to fit poorly & 118 & 7.5 \\
\hline \multicolumn{3}{|c|}{ Source for toll-free number/learning of project } \\
\hline Radio ad & 864 & 56.9 \\
\hline Billboard & 274 & 18.1 \\
\hline Newspaper ad & 134 & 8.8 \\
\hline Community education session & 72 & 4.7 \\
\hline Other & 174 & 11.5 \\
\hline
\end{tabular}

responded to a brief questionnaire which included demographic characteristics, symptoms, risk factors, and the source which prompted their call. Table 1 presents descriptive statistics for the callers. The toll-free hotline appeared to attract the target population with the majority of consenting callers being African American, male, and 40 years of age and older.

Of the media sources, radio ads were reported by more than half of the callers as prompting their call to the toll-free number; billboards were the second most frequently reported source prompting their call, followed by the newspaper ads and education sessions. Most callers reported engaging in risk factors such as having used tobacco or alcohol at some point during their lives, and the most frequently reported symptoms were a sore throat or the feeling of having something caught in the throat and hoarseness or voice changes.

\section{Screenings}

Between April 2005 and June 2008, a total of 1813 screening appointments were made. Eighty percent of those appointments were made by people calling the toll-free number. The remaining $20 \%$ of the appointments were made through direct referrals to the clinic from a dentist or doctor who had heard of the project through the media campaign, from accompanying friends or family to an appointment, or through other direct contact with the clinic.

During this same time period, a total of 1045 people were screened at the free screening clinic in Detroit, and 1020 (99.5\%) consented to participation in the project. Table 2 presents the characteristics and reported symptoms of those who consented and were screened. The majority of persons screened were male, African American, and over 40 years of age. Forty-nine percent of those presenting at the free clinic for screening reported experiencing at least one of six symptoms of oral cancer. The two most frequently reported symptoms by screened participants were hoarseness or voice changes and sore throat or feeling something is caught in the throat. In addition to these symptoms, more than half of those screened reported having smoked at least 100 cigarettes or cigars and slightly more than a third are current smokers. Most of those screened reported ever having consumed alcohol, almost $40 \%$ report drinking at least two or more times per week, and almost $30 \%$ report drinking six or more drinks on any one occasion.

The characteristics of those screened by the source prompting their screening were also examined. The screened participants were divided into three groups: Media referred, Other referred, and No Source specified. Regardless of the source prompting their screening, the characteristics are very similar (Table 2). The majority were male, African American, and 40 years or older, and the two most frequently reported symptoms were the same across sources. Despite the majority being male in each group, there was a significant difference in gender distribution between the Media and Other referred groups $(P=0.005)$. Also, despite it being the second most frequently reported symptom in both groups, there was a significant difference between the Media and Other referred with respect to the proportion of people reporting sore throat as a symptom.

\section{Clinical findings}

Of the 1020 eligible and consenting people screened, $76.0 \%$ resulted in no significant finding. 
Jedele \& Ismail

Table 2. Characteristics of screened and consenting participants by source

\begin{tabular}{|c|c|c|c|c|c|c|c|c|}
\hline & \multicolumn{2}{|c|}{$\underline{\text { Total screened }}$} & \multicolumn{2}{|c|}{$\begin{array}{l}\text { Media } \\
\text { campaign }\end{array}$} & \multicolumn{2}{|l|}{ Other } & \multicolumn{2}{|c|}{$\begin{array}{l}\text { None men- } \\
\text { tioned }\end{array}$} \\
\hline & $N$ & $\%$ & $N$ & $\%$ & $N$ & $\%$ & $N$ & $\%$ \\
\hline Total & 1045 & 100.0 & & & & & & \\
\hline Consenting/eligible & 1020 & 97.6 & 726 & 71.1 & 166 & 16.3 & 128 & 12.5 \\
\hline \multicolumn{9}{|l|}{ Gender $^{\mathrm{a}}$} \\
\hline Male & 631 & 63.7 & 458 & 65.0 & 84 & 51.5 & 89 & 72.4 \\
\hline Female & 360 & 36.3 & 247 & 35.0 & 79 & 48.5 & 34 & 27.6 \\
\hline \multicolumn{9}{|l|}{ Race } \\
\hline Black & 854 & 92.7 & 668 & 93.3 & 144 & 90.0 & 42 & 93.3 \\
\hline White & 46 & 5.0 & 33 & 4.6 & 13 & 8.1 & - & - \\
\hline Other & 21 & 2.3 & 15 & 2.1 & 3 & 1.9 & 3 & 6.7 \\
\hline \multicolumn{9}{|l|}{ Age } \\
\hline 29 years or younger & 56 & 5.5 & 39 & 5.4 & 11 & 6.6 & 6 & 4.7 \\
\hline 30-39 years & 161 & 15.8 & 117 & 16.2 & 27 & 16.3 & 17 & 13.3 \\
\hline 40-49 years & 299 & 29.4 & 208 & 28.7 & 49 & 29.5 & 42 & 32.8 \\
\hline 50-59 years & 337 & 33.1 & 245 & 33.8 & 55 & 33.1 & 37 & 28.9 \\
\hline 60-69 years & 114 & 11.2 & 81 & 11.2 & 18 & 10.8 & 15 & 11.7 \\
\hline 70-79 years & 37 & 3.6 & 25 & 3.5 & 5 & 3.0 & 7 & 5.5 \\
\hline $80+$ years & 14 & 1.4 & 9 & 1.2 & 1 & 0.6 & 4 & 3.1 \\
\hline \multicolumn{9}{|l|}{ Risk factors } \\
\hline \multicolumn{9}{|l|}{ Smoking status } \\
\hline Current smoker & 394 & 38.8 & 270 & 37.3 & 77 & 46.4 & 47 & 37.6 \\
\hline Past smoker & 254 & 25.0 & 182 & 25.1 & 31 & 18.7 & 41 & 32.8 \\
\hline Never smoker & 367 & 36.2 & 272 & 37.6 & 58 & 34.9 & 37 & 29.6 \\
\hline \multicolumn{9}{|l|}{ Current Smokers } \\
\hline Average years smoked & 25.8 & & 24.8 & & 25.6 & & 23.8 & \\
\hline Average cigarettes smoked per day & 12.2 & & 12.0 & & 13.9 & & 11.0 & \\
\hline \multicolumn{9}{|l|}{ Past Smokers } \\
\hline Average years smoked & 15.7 & & 15.8 & & 13.2 & & 16.5 & \\
\hline Average cigarettes smoked per day & 11.9 & & 12.1 & & 11.9 & & 11.4 & \\
\hline \multicolumn{9}{|l|}{ Drinking status } \\
\hline Current drinker & 607 & 65.3 & 471 & 66.2 & 96 & 58.9 & 40 & 74.1 \\
\hline Past drinker & 191 & 20.6 & 148 & 20.8 & 37 & 22.7 & 6 & 11.1 \\
\hline Never drinker & 131 & 14.1 & 93 & 13.1 & 30 & 18.4 & 8 & 14.8 \\
\hline \multicolumn{9}{|l|}{ Drinking frequency (current drinkers) } \\
\hline Monthly or less & 228 & 37.6 & 170 & 36.1 & 46 & 47.9 & 12 & 30.0 \\
\hline 2-4 times a month & 138 & 22.7 & 102 & 21.7 & 22 & 22.9 & 14 & 35.0 \\
\hline $2-3$ times a week & 142 & 23.4 & 118 & 25.1 & 17 & 17.7 & 7 & 17.5 \\
\hline 4 or more times per week & 99 & 16.3 & 81 & 17.2 & 11 & 11.5 & 7 & 17.5 \\
\hline \multicolumn{9}{|l|}{$6+$ drinks on one occasion (current drinkers) } \\
\hline Never & 310 & 51.8 & 240 & 51.8 & 53 & 55.8 & 17 & 42.5 \\
\hline Less than monthly & 109 & 18.2 & 77 & 16.6 & 17 & 17.9 & 15 & 37.5 \\
\hline Monthly & 78 & 13.0 & 62 & 13.4 & 12 & 12.6 & 4 & 10.0 \\
\hline Weekly & 72 & 12.0 & 59 & 12.7 & 9 & 9.5 & 4 & 10.0 \\
\hline Daily or almost daily & 29 & 4.9 & 25 & 5.4 & 4 & 4.2 & & \\
\hline \multicolumn{9}{|l|}{ Symptoms (check all that apply) ${ }^{\mathrm{b}}$} \\
\hline Hoarseness/voice changes & 275 & 27.3 & 201 & 28.0 & 41 & 24.9 & 33 & 26.4 \\
\hline Sore throat/feeling something caught in throat ${ }^{c}$ & 241 & 23.9 & 188 & 26.2 & 27 & 16.4 & 26 & 20.8 \\
\hline Numbness in mouth & 146 & 14.4 & 115 & 15.9 & 17 & 10.4 & 14 & 11.1 \\
\hline Lump in neck, behind ear, under jaw & 134 & 13.4 & 97 & 13.7 & 22 & 13.5 & 15 & 11.9 \\
\hline Persistent ear pain & 108 & 10.8 & 75 & 10.6 & 25 & 15.2 & 8 & 6.5 \\
\hline Swelling causing dentures to fit poorly & 32 & 3.2 & 27 & 3.7 & 3 & 1.8 & 2 & 1.6 \\
\hline Source for toll-free number/learning of project & & & & & & & & \\
\hline Radio ad & 442 & 49.0 & 442 & 60.9 & - & - & - & - \\
\hline Billboard & 126 & 13.9 & 126 & 17.4 & - & - & - & - \\
\hline Newspaper ad & 110 & 12.2 & 110 & 15.2 & - & - & - & - \\
\hline Community education session & 98 & 10.9 & 98 & 13.5 & - & - & - & - \\
\hline Other & 215 & 21.7 & 48 & 6.6 & 166 & 100.0 & - & - \\
\hline Dentist & 66 & 7.6 & 4 & 0.6 & 62 & 47.7 & - & - \\
\hline Family/Friend & 57 & 6.6 & 4 & 0.6 & 53 & 40.8 & - & - \\
\hline
\end{tabular}




\begin{tabular}{|c|c|c|c|c|c|c|c|c|}
\hline & \multicolumn{2}{|c|}{$\begin{array}{l}\text { Total } \\
\text { screened }\end{array}$} & \multicolumn{2}{|c|}{$\begin{array}{l}\text { Media } \\
\text { campaign }\end{array}$} & \multicolumn{2}{|c|}{$\underline{\text { Other }}$} & \multicolumn{2}{|c|}{$\begin{array}{l}\text { None } \\
\text { mentioned }\end{array}$} \\
\hline & $N$ & $\%$ & $N$ & $\%$ & $N$ & $\%$ & $N$ & $\%$ \\
\hline TV (news story about project) & 28 & 3.2 & 28 & 3.9 & - & - & - & - \\
\hline Doctor & 17 & 2.0 & 2 & 0.3 & 15 & 11.5 & - & - \\
\hline Flyer/Brochure (produced by project) & 8 & 0.9 & 8 & 1.1 & - & - & - & - \\
\hline
\end{tabular}

${ }^{a}$ Gender was significantly different between the Media referred and Other referred $(P=0.005)$.

${ }^{\mathrm{b}}$ Screened patients were not asked about the following symptoms: lump on one side of mouth or cheek, and sore on lips for 2+ weeks.

${ }^{\mathrm{c}}$ Reporting of sore throat symptom was significantly different between the Media referred and Other referred $(P=0.01)$.

The project dentist recommended that another $5.2 \%$ return for a follow-up visit to see whether symptoms persisted. A brush biopsy was conducted by the project dentist on $2.1 \%$ of those screened. Once the results of these biopsies were received, the project dentist then determined whether a referral to the oral surgeon was necessary. All brush biopsy results were negative, and no one required a referral to the oral surgeon. For $9.1 \%$ of those screened, the project dentist recommended follow-up with a physician or dentist for other reasons (e.g., tooth extraction and regular cleanings), but no suspicious lesion was found. Table 3 presents the results and diagnoses of the patients screened by the source prompting the patient to come to the clinic for a free screening.
There was a significant difference between the Media and Other referred groups with a higher proportion of the Other referred presenting with a suspicious lesion. Despite this difference, the Other referred group was no more likely to have a cancerous lesion than the Media referred group.

Follow-up was conducted with patients referred to the oral surgeon and diagnosed with precancer, cancer, or other conditions, as well as patients who did not complete the initial referral appointment. These patients were contacted by the project staff and asked to return to the free clinic for a follow-up visit with the project dentist or to at least provide an update on their treatment. Eight of the 47 participants who kept their referral appointment with the oral surgeon were contacted, and all eight

Table 3. Results and diagnoses by source

\begin{tabular}{|c|c|c|c|c|c|c|c|c|}
\hline & \multicolumn{2}{|c|}{$\begin{array}{l}\text { Total } \\
\text { screened }\end{array}$} & \multicolumn{2}{|c|}{$\begin{array}{l}\text { Media } \\
\text { campaign }\end{array}$} & \multicolumn{2}{|c|}{ Other } & \multicolumn{2}{|c|}{$\begin{array}{l}\text { None } \\
\text { mentioned }\end{array}$} \\
\hline & $N$ & $\%$ & $N$ & $\%$ & $N$ & $\%$ & $N$ & $\%$ \\
\hline \multicolumn{9}{|l|}{ Results } \\
\hline No finding & 775 & 76.0 & 568 & 78.2 & 103 & 62.0 & 104 & 81.3 \\
\hline Follow-up with project dentist & 53 & 5.2 & 31 & 4.3 & 11 & 6.6 & 11 & 8.6 \\
\hline Brush biopsy obtained & 21 & 2.1 & 15 & 2.1 & 6 & 3.6 & - & - \\
\hline $\begin{array}{l}\text { Referral to physician/dentist } \\
\text { for other reason }\end{array}$ & 93 & 9.1 & 78 & 10.7 & 14 & 8.4 & 1 & 0.8 \\
\hline Suspicious lesion (referred) & 78 & 7.7 & 34 & $4.7^{\mathrm{a}}$ & 32 & $19.3^{\mathrm{a}}$ & 12 & 9.4 \\
\hline \multicolumn{9}{|l|}{ Diagnoses of those referred ${ }^{b}$} \\
\hline No pathology & 7 & 9.0 & 3 & 8.8 & 3 & 9.4 & 1 & 8.3 \\
\hline Other soft/hard tissue lesions & 17 & 21.8 & 5 & 14.7 & 7 & 21.9 & 4 & 33.3 \\
\hline Benign tumor & 12 & 15.4 & 4 & 11.8 & 8 & 25.0 & - & - \\
\hline Candidiasis & 2 & 2.6 & 1 & 2.9 & 1 & 3.1 & - & - \\
\hline Infection & 3 & 3.9 & 2 & 5.9 & - & - & 1 & 8.3 \\
\hline Xerostomia & 1 & 1.3 & - & - & 1 & 3.1 & - & - \\
\hline Dysplasia & 1 & 1.3 & - & - & - & - & 1 & 8.3 \\
\hline Leukoplakia & 1 & 1.3 & 1 & 2.9 & 1 & 3.1 & - & - \\
\hline Squamous cell carcinoma & 3 & 3.9 & 2 & 5.9 & - & - & 1 & 8.3 \\
\hline No-show & 31 & 39.7 & 16 & 47.1 & 11 & 34.4 & 4 & 33.3 \\
\hline
\end{tabular}

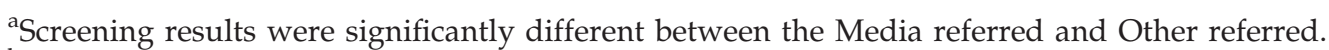

${ }^{b}$ Diagnosis was significantly different between the Media referred and Other referred $(P \leq 0.0001)$; however, no significant difference was observed when diagnosis was categorized into Cancer versus No cancer. 
reported completing the necessary treatment with either the project's oral surgeon or their own dentist. Four of the eight contacted returned for a follow-up visit with the project dentist; the project dentist did not find any evidence of the original condition. Of the 31 who did not see the oral surgeon (i.e., 'no-show'), nine have been contacted. None reported completing any treatment. One of these nine returned for a follow-up, and the project dentist reported no significant finding at this visit.

\section{Education sessions and participants}

Three health educators conducted a total of 242 education sessions with 89 different organizations. A total of 3985 people attended an education session with an average of 16.5 consenting participants in each education session. The majority of education sessions were conducted with substance abuse treatment programs $(57.9 \%)$ followed by senior citizen programs (11.2\%), shelters (7\%), religious/spiritual organizations (6.2\%), community-based organizations (5.8\%), schools or adult educational programs $(5.4 \%)$, unions or employment organizations $(3.7 \%)$, health clinics $(2.1 \%)$, and various other organizations $(0.8 \%)$. Sixty-four percent of the participants attending one of these education sessions attended a session conducted in a substance abuse treatment program.

Session participants are described in detail in Table 4. The education sessions also seemed to reach the targeted population with the majority of the session participants being African American, male, and 40 years of age and older. The majority of the session participants had at least a high school education. Session participants were not asked whether they were experiencing any symptoms of oral cancer.

When asked about oral cancer screening in the presession, more than half of the participants reported having ever heard of oral cancer screening, yet fewer than $10 \%$ of the participants reported having ever been screened. Of those never having been screened, more than three-quarters reported that they would get screened. The most commonly reported reasons for never having been screened were not thinking one was at risk; not being able to afford the doctor or dentist; not being aware of oral cancer or screening; fear of a cancer diagnosis; and fear that screening would be painful.

Less than half of the education session participants reported that they had heard of free oral cancer screening in Detroit. The majority of participants reported hearing about free oral cancer
Table 4. Beliefs and knowledge about oral cancer: education session participants

\begin{tabular}{lrr}
\hline & $N$ & $\%$ \\
\hline Oral cancer is a disease that involves the mouth, throat, \\
or lips & 2424 & \\
Strongly agree & 1072 & 28.5 \\
Agree & 148 & 3.9 \\
Neither agree nor disagree & 77 & 2.1 \\
Disagree & 40 & 1.1 \\
Strongly disagree & & \\
I think oral cancer can be prevented & 1724 & 46.6 \\
Strongly agree & 1332 & 36.0 \\
Agree & 397 & 10.7 \\
Neither agree nor disagree & 172 & 4.7 \\
Disagree & 73 & 2.0 \\
Strongly disagree &
\end{tabular}

Oral cancer is a common cancer for African-American men in Detroit

$\begin{array}{lrr}\text { Strongly agree } & 1013 & 27.5 \\ \text { Agree } & 912 & 24.8 \\ \text { Neither agree nor disagree } & 1058 & 28.8 \\ \text { Disagree } & 468 & 12.7 \\ \text { Strongly disagree } & 227 & 6.2\end{array}$

Strongly disagree the nation

$\begin{array}{lrr}\text { Strongly agree } & 918 & 25.0 \\ \text { Agree } & 868 & 23.7\end{array}$

Neither agree nor disagree $\quad 1380 \quad 37.6$

Disagree $\quad 419 \quad 11.4$

Strongly disagree $\quad 85 \quad 2.3$

Oral cancer screening attitudes and behaviors

Ever heard of oral cancer screening

$\begin{array}{lll}\text { Yes } & 1935 & 52.7\end{array}$

$\begin{array}{lll}\text { No } & 1602 & 43.6\end{array}$

$\begin{array}{lll}\text { Don't know } & 137 & 3.7\end{array}$

Ever been screened for oral cancer

$\begin{array}{lll}\text { Yes } & 233 & 6.4\end{array}$

$\begin{array}{lrr}\text { No } & 3315 & 90.4\end{array}$

Don't know $\quad 118 \quad 3.2$

Would you ever get screened

$\begin{array}{lll}\text { Yes } & 2607 & 76.9\end{array}$

$\begin{array}{lrr}\text { No } & 298 & 8.8\end{array}$

Don't know $485 \quad 14.3$

(If never screened) Why haven't you been screened

Don't think I am at risk $\quad 740 \quad 25.5$

$\begin{array}{lll}\text { Afraid to find out I have cancer } & 686 & 23.7\end{array}$

Can not afford to go to DDS/MD $\quad 396 \quad 10.5$

Afraid screening would be painful $\quad 262 \quad 9.0$

$\begin{array}{lll}\text { Other reason } & 158 & 4.2\end{array}$

Didn't know about oral cancer $\quad 120 \quad 4.1$

Didn't know about screening $\quad 68 \quad 1.8$

$\begin{array}{lll}\text { Relies on DDS to screen } & 63 & 1.7\end{array}$

$\begin{array}{lll}\text { Never thought about it } & 37 & 1.0\end{array}$

Didn't know where to go $\quad 28 \quad 0.8$

$\begin{array}{lll}\text { Physician never mentioned } & 23 & 0.6\end{array}$

$\begin{array}{lll}\text { No opportunity } & 17 & 0.5\end{array}$

I would get screened $\quad 14 \quad 0.4$

$\begin{array}{lll}\text { Didn't know about 'it' } & 2 & 0.1\end{array}$

Evaluation of the media campaign

Ever seen or heard about free oral cancer screening

$\begin{array}{lrr}\text { Yes } & 1655 & 45.6 \\ \text { No } & 1893 & 52.1 \\ \text { Don't know } & 83 & 2.3\end{array}$


Table 4. (Continued)

\begin{tabular}{lrr}
\hline & $N$ & $\%$ \\
\hline Source for finding out about free oral cancer screening \\
(all that apply) & & \\
Community education session & 1002 & 61.8 \\
Billboard & 243 & 15.0 \\
Radio ad & 240 & 14.8 \\
Newspaper ad & 88 & 5.4 \\
Other program/organization & 46 & 2.8 \\
Other media & 21 & 1.3 \\
Doctor/dentist & 19 & 1.2 \\
Other people & 18 & 1.1 \\
Therapist/counselor & 7 & 0.4 \\
School & 6 & 0.4 \\
Knew someone with it & 5 & 0.3 \\
Brochure/flyer (produced by project) & 5 & 0.3 \\
\hline
\end{tabular}

screening from the education session, and $57 \%$ of all session participants endorsed 'education session' as the only source, suggesting that they were hearing about the project's free oral cancer screening for the first time in that session. Billboards and radio ads were the second and third most frequently reported media sources for hearing about oral cancer screening. Other sources for hearing about the project's free screening included newspaper articles and advertisements, other programs and organizations, other media not origi- nally part of the campaign, and other people (e.g., family, friends, doctors, and dentists).

Repeated measures analyses controlling for age of the participant, type of organization holding the session, number of participants in the session, and educator show significant increases in knowledge from the presession to the postsession (Table 5) with one exception. Fewer participants correctly responded to family history of cancer as a risk factor in the postsession. One explanation for this observation is that the family history was not discussed as part of the education presentation.

\section{Impact of the media campaign}

During the course of the 2-year campaign, a total of 1327 radio ads were aired on three local radio stations. Approximately 33 radio ads were aired per week. Twenty-five billboards were displayed between April and August 2005; 15 were displayed between September and October 2005, January and March 2006, and May and August 2006; two were displayed between October 2006 and June 2007 and in October 2007; 1 was displayed in September and October 2007. Two newspaper ads were run between April and August 2005.

A bivariate analysis comparing the frequency of media, scheduling, and screening with the number

Table 5. Correct responses to risk factors of oral cancer in the pretest versus posttest

\begin{tabular}{|c|c|c|c|}
\hline & \multirow{2}{*}{$\frac{\text { Pretest }}{\% \text { Correct }}$} & \multirow{2}{*}{$\frac{\text { Posttest }}{\% \text { Correct }}$} & \multirow[b]{2}{*}{$P^{\mathrm{a}}$} \\
\hline & & & \\
\hline \multicolumn{4}{|l|}{ Knowledge } \\
\hline $\begin{array}{l}\text { Oral cancer is a disease that involves the mouth, } \\
\text { throat or lips }{ }^{b}\end{array}$ & 92.9 & 98.3 & $* * *$ \\
\hline I think oral cancer can be prevented ${ }^{\mathrm{b}}$ & 82.7 & 92.4 & $* * *$ \\
\hline $\begin{array}{l}\text { Oral cancer is a common cancer for } \\
\text { African-American men in Detroit }{ }^{b}\end{array}$ & 52.0 & 93.3 & $* * *$ \\
\hline $\begin{array}{l}\text { Detroit has one of highest death rates from oral } \\
\text { cancer in the nation }\end{array}$ & 48.3 & 92.7 & *** \\
\hline \multicolumn{4}{|l|}{ Risk factors } \\
\hline Family history of cancer & 57.2 & 49.9 & $* * *$ \\
\hline Low consumption of fruits and vegetables ${ }^{b}$ & 39.9 & 79.4 & $* * *$ \\
\hline Use of cigarettes ${ }^{\mathrm{b}}$ & 86.7 & 94.2 & $* * *$ \\
\hline Use of cigars or pipes ${ }^{b}$ & 77.7 & 89.0 & $* * *$ \\
\hline Use of chewing tobacco ${ }^{b}$ & 73.9 & 86.9 & $* * *$ \\
\hline Use of alcohol ${ }^{\mathrm{b}}$ & 50.0 & 87.7 & $* * *$ \\
\hline Poor oral hygiene ${ }^{b}$ & 66.9 & 83.4 & $* * *$ \\
\hline Older age & 33.2 & 68.7 & $* * *$ \\
\hline Use of spicy foods & 42.4 & 53.5 & $* * *$ \\
\hline Certain types of viruses (Herpes, HIV) ${ }^{\mathrm{b}}$ & 46.0 & 72.3 & $* * *$ \\
\hline \multicolumn{4}{|l|}{ Screening behaviors } \\
\hline Ever heard of oral cancer screening (\% yes) & 52.9 & 74.7 & $* * *$ \\
\hline Ever get screened ( $\%$ yes) & 76.9 & 88.5 & $* * *$ \\
\hline
\end{tabular}

a Significance results from repeated measures analysis controlling for participant age, organization type, number of participants in the session, and educator.

${ }^{\mathrm{b}}$ Topic, issue, risk factor was presented during the education session. 
of calls to the toll-free hotline was conducted to assess the impact of each of the components of the campaign and to determine whether calls were resulting in scheduled appointments and actual screenings. The analysis showed that the number of calls to the toll-free hotline was positively associated with the number of billboards (Pearson's $r=0.68 ; P \leq 0.0001$ ) and radio ads (Pearson's $r=0.69 ; P \leq 0.0001)$. Newspapers and education sessions were not associated with calls to the tollfree hotline. Calls to the toll-free hotline resulted in scheduled appointments (Pearson's $r=0.78$; $P \leq 0.0001$ ) and screening of patients (Pearson's $r=0.67 ; P \leq 0.0001)$.

\section{Project costs}

The costs associated with encouraging people to call the toll-free hotline (i.e., management of tollfree hotline, radio and newspaper ads, billboards, brochures, and education sessions) totaled $\$ 760$ 015.56. This resulted in an average of $\$ 424$ per call. The costs associated with the education sessions totaled $\$ 19699.78$ resulting in a cost of $\$ 81.40$ per session and $\$ 494$ per session participant.

The total cost of the project, including the media campaign (i.e., billboards, radio ads, newspaper ads, brochures, posters, and toll-free hotline), the screening clinic (i.e., clinic rental, salaries, and materials), biopsy costs (i.e., cost of the kits), and education sessions (i.e., salaries and materials), totaled $\$ 795$ 898.03. This resulted in a cost of $\$ 761$ per screened case and $\$ 159180$ per precancer and cancer detected.

\section{Discussion}

A multifaceted media campaign including radio ads and billboards coupled with a community education program proved to be effective in increasing awareness of and screening for oral cancer among a high-risk population at a relatively low cost. More than one thousand people were screened, and more than 3500 people participated in an education session. Radio ads appeared to be the most successful media outlet for soliciting calls to the toll-free hotline and for scheduling screening appointments; the billboards were the second most frequently reported source. The project was fortunate to attract the attention of a major local news program and two well-read local newspapers which provided an additional means of informing the public about oral cancer as well as advertising the free screening program. These outlets ran stories describing the project and provided the toll-free number and screening information.

The education sessions could potentially have resulted in a larger number of people receiving a free screening from the project. Several organizations for whom an education session was conducted inquired about on-site screening, because many of their residents were unable to leave the facility (e.g., in-patient substance abuse treatment or senior citizens who were physically unable to travel to the clinic). Anecdotally, participants in such organizations also expressed an interest in receiving a screening; however, they lacked transportation or the ability to leave the facility. Unfortunately, the project was not able to accommodate on-site screening because of a lack of portable equipment and staff availability.

The project focused on African-American men in the city of Detroit and Wayne County. A series of billboards and radio ads were produced specifically targeting this population with culturally relevant messages. Focus groups were convened to educate the researchers on the issues that are important and relevant to this population and how best to attract the attention of those most in need of the message. The project was successful in targeting this high-risk population in that more than half of all participants, callers, and those screened were male, and more than $80 \%$ reported being African American.

There is clearly a continued lack of awareness regarding oral cancer risk factors and the need for screening among this population in Detroit. Results from the education sessions show that most Detroiters have never been screened nor were they aware that oral cancer was something for which you could be screened. However, after a brief 30-minute presentation, participants showed an increase in knowledge and awareness of oral cancer. It is encouraging to note that most of the participants despite never having been screened would likely get a screening. It is also worth noting that the reasons for not being screened are mostly ones that can be addressed. Participants mentioned not being screened because they thought they were not at risk, feared a cancer diagnosis, and feared screening would be painful. The project's education session addressed all of these reasons with discussions of the risk factors associated with this population, the importance of and successful outcomes associated with early detection, and the ease and painlessness of screening. 
A need for free or low-cost screening became evident throughout the project as the inability to afford medical or dental care was a frequently reported reason for not having been screened. Also necessary is support, financial as well as social, for those identified with suspicious lesions to receive further diagnosis and possible treatment. The project recognized the financial need and as part of the referral process was able to offer financial assistance to those without medical or dental insurance. A total of 45 people applied for and received financial assistance through support provided to the project. Further efforts to support the patients in the project included the attempts at following-up with those referred to the oral surgeon. Unfortunately, this effort proved unsuccessful as only $23 \%$ of the patients were contacted. But for those contacted, treatment was either completed, or evidence of the original problem was no longer present.

Decreases in the number and ultimate cessation of radio ads played resulted in a drop in the number of calls and scheduled appointments. A total of 30 calls were received by the hotline in the 5 months (an average of six per month) following the end of the campaign; whereas during the campaign, an average of 49 calls was received each month. Other studies have documented this lack of sustainability. Hirst et al. 1990 noted that during the first month after the campaign, cervical cancer screening remained elevated; however, during the second and third months after campaign, the rate returned to slightly below precampaign levels. Mullins et al. reported a similar return to normal screening rates following a 22-week campaign to encourage women who were overdue for a Papanicolaou test to come in for screening. A concerted effort to raise awareness must be made to sustain screening rates until oral cancer risk, and the necessity for screening is as much a part of the public's vocabulary as breast cancer and mammography have become.

It is not possible to test with this project whether overall screening rates in Detroit rose during the campaign. Data on screening rates in Detroit are not available, and the project did not assess general population rates prior to, during, or after the campaign. The primary outcome measures of the media campaign proposed were the oral cancer incidence and mortality statistics in Michigan. At the time of this analysis, statistics for the campaign time period were not available. Once those statistics are released, the project will be able to assess the success of the campaign with respect to oral cancer incidence and mortality rates.

The cost per case may be considered quite high and prove to be prohibitive. However, the higher cost is attributed to the project's evaluation of multiple media outlets and providing free screening in addition to free community education sessions. Costs could be reduced by acquiring a sponsor and using the campaign as a means to promote evidence-based health products that reduce one's risk of being diagnosed with oral cancer, e.g., nicotine replacement therapies, or as this project discovered, focusing on one media outlet (i.e., radio). Despite the cost, the return on the investment of saving human lives cannot be valued.

The campaign described in this article had the potential to reach over 2 million residents in the Detroit metropolitan area, and at the present time we cannot fully assess its impact. The overall incremental cost of saving one life is expected to be significantly lower once incidence and mortality data from the Michigan Cancer Registry are analyzed. Once the data are made available, we plan to compare the Detroit Tri-County (Wayne, Oakland, Macomb) area with respect to the incidence and mortality rates during the course of the campaign with seven comparison counties also in Michigan.

This evaluation shows that a social marketing mass media campaign can effectively target a highrisk population and given an outlet can result in a large number of people getting screened and also in lives saved.

\section{Acknowledgements}

This study was funded by the National Institute of Dental and Craniofacial Research/National Institutes of Health Grants DE14410-03 and DE16194-01 and through a grant from the Delta Dental Fund, an affiliate of the Delta Dental Plan of Michigan.

\section{References}

1. Ries LAG, Eisner MP, Kosary CL, Hankey BF, Miller BA, Clegg L et al. (eds). SEER Cancer Statistics Review, 1975-2001, National Cancer Institute. Bethesda, MD. Available at: http://seer.cancer.gov/csr/ 1975_2001/, 2004 [last accessed 21 April 2008].

2. American Cancer Society Cancer facts and figures for African Americans 2007-2008. Atlanta, GA: American Cancer Society; 2008. Available at: http:// www.cancer.org/downloads/STT/CAFF2007AAacs pdf2007.pdf [last accessed 21 April 2008]. 
3. U. S. Census Bureau. (2000). American Factfinder, Summary File 1. Available at: http:/ / factfinder.census.gov [last accessed 8 November 2008].

4. Kolker JL, Ismail AI, Sohn W, Ramaswami N. Trends in the incidence, mortality, and survival rates of oral and pharyngeal cancer in a high-risk area in Michigan, USA. Community Dent Oral Epidemiol 2007;35:489-99.

5. Yellowitz JA, Goodman HS, Farooq NS. Knowledge, opinions, and practices related to oral cancer: results of three elderly racial groups. Spec Care Dentist 1997;17:100-4.

6. Horowitz AM, Canto MT, Child WL. Maryland adults' perspectives on oral cancer prevention and early detection. J Am Dent Assoc 2002;133:1058-63.

7. Cruz GD, Le Geros RZ, Ostroff JS, Hay JL, Kenigsberg HT, Franklin DM. Oral cancer knowledge, risk factors and characteristics of subjects in a large oral cancer screening program. J Am Dent Assoc 2002;133:1064-71.

8. Stahl S, Meskin LH, Brown LJ. The American Dental Association's oral cancer campaign. J Am Dent Assoc 2004;135:1261-7.

9. Horowitz AM, Nourjah P, Gift HC. U.S. adult knowledge of risk factors and signs of oral cancers: 1990. J Am Dent Assoc 1995;126:39-45.

10. Tomar SL, Logan HL. Florida adults' oral cancer knowledge and examination experiences. J Public Health Dent 2005;65:221-30.

11. Horowitz AM, Moon H, Goodman HS, Yellowitz JA. Maryland adults' knowledge or oral cancer and having oral cancer examinations. J Public Health Dent 1998;58:281-7.

12. Canto MT, Drury TF, Horowitz AH. Use of skin and oral cancer examinations in the United States, 1998. Prev Med 2003;37:278-82.

13. Horowitz AM, Nourjah P. Factors associated with having oral cancer examinations among US adults 40 years of age or older. J Public Health Dent 1996;56:331-5.

14. Choi Y, Dodd V, Watson J, Tomar ST, Logan HL, Edwards H. Perspectives of African Americans and dentists concerning dentist-patient communication on oral cancer screening. Patient Educ Couns 2008;71:41-51.

15. Powe BD, Finnie R. Knowledge of oral cancer risk factors among African Americans: do nurses have a role? Oncol Nurs Forum 2004;31:785-91.

16. Kotler P, Zaltman G. Social marketing: an approach to planned social change. J Mark 1971;35:3-12.

17. Walsh DC, Rud RE, Moeykens BA, Moloney TW. Social marketing for public health. Health Aff 1993;Summer:104-19.

18. Andreasen AR. Marketing social change. Introduction. San Francisco: Jossey-Bass Publishers; 1995.

19. Kotler P. Social Marketing. Chapter 1 and 2. New York: The Free Press; 1989.

20. Jenkins CNH, McPhee SJ, Bird JA, Pha GQ, Nguyen $\mathrm{BH}, \mathrm{Nguyen} \mathrm{T}$ et al. Effect of a media-led educational campaign on breast and cervical cancer screening among Vietnamese-American women. Prev Med 1999;28:395-406.

21. Hirst S, Mitchell H, Medley G. An evaluation of a campaign to increase cervical cancer screening in rural Victoria. Community Health Stud 1990;14:263-8.

22. Michielutte $R$, Dignan $M$, Wells HB, Young L, Jackson D, Sharp P. Development of a community cancer education program: the Forsyth County NC Cervical Cancer Prevention Project. Public Health Rep 1989;104:542-51.

23. Nguyen TT, Vo PH, McPhee SJ, Jenkins CNH. Promoting early detection of breast cancer among Vietnamese-American women: results of a controlled trial. Cancer 2001;91(Suppl. 1):267-73.

24. Broadwater C, Heins J, Hoelscher C, Mangone A, Rozanas C. Skin and colon cancer media campaigns in Utah. Prev Chronic Dis 2004;1:1-6.

25. Papas RK, Loga HL, Tomar SL. Effectiveness of a community-based oral cancer awareness campaign (United States). Cancer Causes Control 2004;15:12131.

26. Gordon R, McDermott L, Stead M, Angus K. The effectiveness of social marketing interventions for health improvement: what's the evidence? Public Health 2006;120:1133-9.

27. Mullins R, Wakefield M, Broun K. Encouraging the right women to attend for cervical cancer screening: results from a targeted television campaign in Victoria, Australia. Health Educ Res 2007; doi: 10.1093/her/cym021.

28. Pasick RJ, Hiatt RA, Paskett ED. Lessons learned from community-based cancer screening intervention research. Cancer 2004;101(Suppl. 5):1146-64.

29. Lam TK, McPhee SJ, Mock J, Wong C, Doan HT, Nguyen $\mathrm{T}$ et al. Encouraging Vietnamese-American women to obtain pap tests through lay health worker outreach and media education. J Gen Intern Med 2003;18:516-24.

30. Nguyen TT, McPhee SJ, Gildengorin G, Nguyen T, Wong C, Lai KQ et al. Papanicolaou testing among Vietnamese Americans: results of a multifaceted intervention. Am J Prev Med 2006;31:1-9.

31. Black ME, Yamada J, Mann V. A systematic literature review of the effectiveness of community-based strategies to increase cervical cancer screening. Can J Public Health 2002;93:386-93.

32. Mock J, McPhee SJ, Nguyen T, Wong C, Doan H, Lai $\mathrm{KQ}$ et al. Effective lay health worker outreach and media-based education for promoting cervical cancer screening among Vietnamese American women. Am J Public Health 2007;97:1693-700.

33. Marcus AC, Crane LA. A review of cervical cancer screening intervention research: implications for public health programs and future research. Prev Med 1998;27:13-31.

34. Holland BK, Foster JD, Louria DB. Cervical cancer and health care resources in Newark, New Jersey, 1970 to 1988. Am J Public Health 1993;83:45-8.

35. Kotler P. Marketing management, 11th Edn. Upper Sadle River, NJ: Pearson education Inc.; 2003;511. 